\title{
EVALUATING INDIVIDUAL CONTRIBUTIONS TO GROUP PROJECTS
}

\author{
Derek COVILL', Tim KATZ ${ }^{1}$, Steven SMITH ${ }^{2}$ and Dan HICKS ${ }^{1}$ \\ ${ }^{1}$ School of Computing, Engineering \& Mathematics, University of Brighton, United Kingdom \\ ${ }^{2}$ School of Architecture and Design, University of Brighton, United Kingdom
}

\begin{abstract}
This study describes a method of setting and assessing group projects that has been developed and successfully implemented on our undergraduate Engineering and Product Design degrees for over 10 years. A simple weighted-matrix method, applied in Excel, generates a weighting factor based on a peer assessment of the contribution and effort of each student. This weighting factor, when multiplied by the group mark, is used to calculate an individual student's mark. The methodology used was reviewed considering relevant literature in the fields of group project learning and project-based learning, with implications for large cohorts discussed. Finally, two case studies are examined with issues and resolutions highlighted.
\end{abstract}

Keywords: Group, individual, contribution, assessment, validity, accuracy

\section{INTRODUCTION}

Group projects are used widely throughout the HE sectors to teach students the important life skills of negotiation and collaboration. Yet, despite these compelling educational (and administrative) advantages, the validity and rigor of our higher/tertiary education system requires individual student grades for any given assignment. The authors have developed a system for extracting individual marks from group work which is believed to be rigorous, transparent and robust enough to mitigate appeals. After outlining some useful insights from the literature on assessing group projects, our process of setting up, supervising, assessing, processing and interpreting results is then described. We then outline two recent case studies from engineering and product design with large and medium-sized cohorts, using large and small group sizes and we discuss the various issues and key questions that arise from such activities.

\section{LITERATURE REVIEW}

Large, complex projects are commonplace in the professional world and require personnel that have both individual talent as well as the ability to work effectively in groups [1]. Teamwork is an almost ubiquitous request in job adverts and is referenced explicitly in many accrediting professional bodies, including, but not limited to, the IED, IET, IMechE [2]. Consequently, learning how to work effectively in groups has become a core skill and one that undergraduates need exposure to, and practice at. Integrating this group work in undergraduate degrees allows it to be constructively aligned with the established learning outcomes [3]. The need for individual student marks means that, while group-based projects are valuable, they must retain the differential incentive of rewarding individual effort and contribution [4]. If the onus of resolving these individual grades is placed on academics, an unreasonable level of supervision may be required; this is where peer-assessment (where students assess themselves and each other) can be utilised. However, care must be paid when forming these tasks as without careful consideration it can fail to reduce academic burden [5]. As part of their guide to designing and managing team assignments, [11] seemed to discourage activities with groups larger than 5. However, the authors would argue that there are real benefits to working in larger groups where formal teamwork methodologies, which are used extensively in industry, must be used. The reliability, accuracy and consistency of peer assessment $[6,7]$ and even the accuracy of the mark from a professional assessor [8] can readily be called into question necessitating considered controls to improve accuracy. Qualitatively defining a numeric scale can be seen in [9], which proposes an 'Autorating' method for determining an individual weighting factor for a group mark based on self and peer-assessments using 
a 9-point scale. While clearly an effective approach, it seems to focus on prioritising an approach that is hands-off rather than one that is beneficial for student learning. In assessing the validity of the 'Autorating' method, [10] demonstrated a good agreement between previously determined grades and those calculated using that method, although the student activities undertaken were relatively limited in scope (i.e. homework activities and assignments for exams as opposed to large, open projects). Peer assessment relies on a variation in the perception of effort, quality and expectation within a team. Inexperience in working in diverse teams, trying to establish a shared common identity and a lack of 'professionality' (criticism about a task being taken personally or vice versa) are common reasons for conflict [12]. Research shows that when marking group work, educators need to distinguish between marking the process: how well did the group function; and the outcome: how well did the group function [13]. This thinking has been applied in the projects described below, where a summative assessment with the mark awarded for that task open to change depending on how much everyone has contributed. Finally, it is important to provide the chance for students to reflect on what worked and what failed during the project as well as on the process itself [14]. This stage is not only a further opportunity to reinforce the learning around which the project is structured, but a chance to reflect on the influence (for good or bad) of working within a team.

\section{THE PROCESS: MARKING INDIVIDUAL CONTRIBUTIONS IN GROUP PROJECTS}

\subsection{Setting up projects}

Approaching students as stakeholders improves the quality of their participation. The process, benefits and limitations are explained, negotiated and then approved by all participants. A verbal consensus seems to be acceptable here. An explicit description of the standards expected of group behaviour should be agreed by the end of the introductory session. Group allocation can either be by student choice or randomised or imposed by staff, depending on the learning outcomes of the assignment. Self-selection can leave students unwanted by other groups. Whilst this may be an important personal learning opportunity for those concerned, staff may need to monitor and intervene as some students may feel (and in cases be) unfairly omitted due to discrimination or prejudice. A good methodology to form new groups is to prepare a post-it packs with sequential group numbers (e.g. A1, A2, A3 ... E4, E5, etc.). Hand out these post-it's to the students as they enter the lecture theatre, then, if they have arrived with their friends, they will all be assigned to different groups. Any absent students can easily be assigned to the "next group on the pile". It is important that staff then fix the group members at an early opportunity to minimise swaps. Students can be asked to sign the post-it and submit them on their group sheet, with names and contact numbers for each other.

\subsection{Supervising projects}

Once the assignment has been introduced, a clear scheduling framework with intermediate goals is set out which helps students plan and set their own group deadlines. Staff then assign a shared space that is neutral, accessible and which can be monitored. Depending on the nature of the work, this can either be digital (such as, Blackboard, Moodle etc), or physical (such as the workshop or Studio). Throughout the project regular tutorial support gives teams the opportunity to respond to group issues and staff the chance to register attendance, monitor progress and to keep track of individual efforts. Quick and relevant formative critics - peer marked against clear criteria - are a further way to gauge individual contributions and are good points at which to mediate any dysfunctional group dynamics.

\subsection{Assessing projects}

The summative assessment is carried out according to the brief with marking carried out by staff against pre-determined criteria. This generates the underlying group mark. There follows a team evaluation process which generates the weighting factor that will be applied to assign individual grades. The evaluation requires all team members to assign their partners and themselves a mark from 0 to 5 according to the following descriptions outlined in Table 1. This mark gives a weighting as to their contribution and effort within the team, where their fellow team members have good authority. Contribution is defined as a quality measure: good work is influential and can strongly influence the team dynamic and assignment outcome. Effort is a quantitative measure: it may influence general group dynamics and the motivation of the team. 
Table 1. Classification and descriptors for students to score themselves and each other

\begin{tabular}{|c|l|}
\hline Classification & \multicolumn{1}{c|}{ Descriptor } \\
\hline 0 & $\begin{array}{l}\text { Rarely present at sessions and made no contribution, or has been present but actively } \\
\text { destructive in their contributions }\end{array}$ \\
\hline 1 & Has been present but made no attempt to contribute \\
\hline 2 & Has contributed under duress and/or quality was unsatisfactory \\
\hline 3 & Team player, doing what was required and of usable quality \\
\hline 4 & Volunteers activity and contribution, engaging in the assignment \\
\hline 5 & Very pro-active, initialising activity and taking on important roles with high quality outcomes \\
\hline
\end{tabular}

Students submit a confidential Statement of Relevance (SoR); a critical and reflective account of the assignment and the group dynamics in which there is a requirement for them to justify their group evaluations.

\subsection{Processing and interpreting results}

Marks are calculated using a spreadsheet, but the tutor needs to remember that these are "decision numbers" so care must be taken about their implied rigor in the processing, as they come from a subjective source. The rows of the table represent how an individual is evaluated, whilst the columns show each student's evaluation of themselves and others in the team. The average of each row divided by the average of the table gives the individual weighting factor. When multiplied by group mark this produces the individual student mark.

\begin{tabular}{|c|c|c|c|c|c|}
\hline$\Delta$ & A & B & C & D & $\mathrm{E}$ \\
\hline 1 & & John & Mary & & \\
\hline 2 & John & 4 & 4 & =average $(\mathrm{B} 2: \mathrm{C} 2)$ & $=D 2 / \$ D \$ 4$ \\
\hline 3 & Mary & 4 & 3 & =average (B3:C3) & $=D 3 / S D S 4$ \\
\hline 4 & & $=$ average $(\mathrm{B} 2: \mathrm{B} 3)$ & $=$ average $(\mathrm{C} 2: \mathrm{C3})$ & =average $(\mathrm{B} 2: \mathrm{C} 3)$ & \\
\hline
\end{tabular}

\begin{tabular}{l|c|c|c|c|c|}
\multicolumn{1}{c|}{ A } & A & \multicolumn{1}{c|}{ B } & \multicolumn{1}{c|}{ C } & \multicolumn{1}{c|}{ D } & \multicolumn{1}{c|}{ E } \\
\cline { 2 - 6 } 1 & & John & Mary & & \\
\hline \cline { 2 - 6 } 2 & John & 4 & 4 & 4.00 & 1.07 \\
\hline 3 & Mary & 4 & 3 & 3.50 & 0.93 \\
\hline 4 & & 4.00 & 3.50 & 3.75 & \\
\hline
\end{tabular}

Figure 1. An example formula sheet in MS excel for a 2-person group (left), with the resulting data with weighting factors for each student highlighted (right)

In addition to processing the table, the tutor needs to carefully analyse the results and to be alert to the tell-tale signs of:

- Collusion between some group members and the formation of cliques.

- Vendettas: sometimes tribal splits open along lines of technical discipline, cultural or even racial differences. These need to be actioned appropriately as per University policy.

- Outlying individuals: proactive and effective leaders are easily highlighted, as are those who have contributed little. Other typical profiles that can be identified are self-promoters who exaggerate their input and diffident students that undervalue theirs.

Reference to the teams' shared workspace can help the tutor better understand the politics of the group interactions and give insights into some of the situations describe above. There should be file sharing records, where contributions are made, and action lists or group meeting minutes are available for scrutiny. If the tutor decides to override any of the students' self or peer classification, notes should be kept that justify the reasons either to students or Examination Boards. Academic judgment is completely in the staff domain, so although the students do not have a right to appeal the mark, they are perfectly entitled to have decisions clarified. Consequently, there need to be clear records.

Finally, feedback and review are an important stage. Students marks and SoRs are returned with comments. Generally, the tutor will also need to put aside some time to address misunderstandings and queries both on a group basis as well as one-to-one. This part of the process can be difficult as some individuals come to realise that their perception of the role in the group is not shared by others.

\section{CASE STUDY A}

In an engineering project during the 16-17 academic year there were 22 active teams of 7 . Initially, the number of teams that questioned the peer marks was 3, but once the share was worked out only 6 out of 157 registered students sought a review. These reviews highlighted some of the intriguing issues that sometimes arise and how they may be dealt with: 
- Bullying or abuse: A student was insulted with inappropriate language during a WhatsApp dialogue when they were absent from a team meeting. The student showed the conversation to the tutor who called in the group to deal with this unacceptable behaviour. It appeared that both the abused student and his abusers were, in fact, friends who got over-heated in the stress of the moment. The evaluations were used to assign the self-evaluation classification as identical to that given to the victim. As this was part of a management module, the unprofessional behaviour (which they all agreed was inappropriate in a professional context) was challenged but the matter not taken any further.

- Collusion: A team had a group of friends that all gave each other the top classification, but then distributed the classifications more meagrely elsewhere. The others in the team were more discerning about diverse contributions within the friendship group. Also, the critically reflective statements within the team were markedly different: there was a far higher critical ability and honesty shown by a team member who differentiated between the friends. After viewing the activity on our online learning platform, it was decided to remove the evaluations of the friends, leaving only those from the others. Two of the friends asked for a review and the tutor team has asked for written statements from all the team members and delivered an appropriate response: collusion is a form of cheating and may be a disciplinary concern.

- Self-deprecating or self-promoting behaviour: Students were either modest or inflationary in declaring their true contribution. Others within the team all classified them within a narrow range of contribution and effort (whether high or mediocre), giving a consistent and coherent view from their colleagues. This gave them a slightly lower / higher share of the group mark but was not altered by the staff team unless there was a distinct difference between their own self-assessment and the team's. Then the self-evaluation was brought within the groups' variance.

- Team splits: A team (made up of two different disciplines) separated into two groups where each perceived the other as less effective than themselves. This may have been due to their lack of understanding of the other discipline. Classifications were not changed in this case, as their misunderstandings cancelled each other out. It was also interesting to note that this mutual distrust and lack of cohesion resulted in a weaker group outcome.

\section{CASE STUDY B}

In a design project during the 2016-17 academic year, students were split into 20 teams of between 2 and 3 students. The project's timing, early in the first year, meant that staff and students were not able to arrange groups in terms of personality or skill set, so the combinations were random. At the end of the project, only one of the teams questioned their marks and only 1 out of 50 sought a review. In addition to some of the problems encountered above, the following issues arose during the evaluation process:

- The impact of age: One of the teams comprised of two mature students who had different ambitions for the project and a third, much younger 'neutral' student. It was observed that the dynamic of the group was not dissimilar to competitive parents manipulating a child's emotions. Separately, the older students would make their case to the younger one and then, during tutorials look to the younger student for support. Interestingly, at the evaluation phase, the two older students marked the younger one significantly lower than themselves, whilst the younger student's scores were evenly spread. Tutors compensated the younger student's final mark upwards, though it was clear that they had found it difficult to have much impact on the project when trapped between the opposing egos of their teammates.

- The impact of language/culture: One of the groups included an exchange student from overseas. In many ways, an excellent student, but they did struggle considerably with language skills. This presented two difficulties. Firstly, all students were expected to apply material delivered in lectures to their project and this meant that one of the team had to continually explain parts of the teaching the overseas student had either misunderstood or not fully grasped. The other issue was when they started to explore solutions, communicating their intent was difficult, so that the team was forced to share and develop ideas using non-verbal methods such as drawing or modelling. This team achieved the highest project mark, though whether this was due to natural ability or having to go back over teaching material or the more hands-on approach they adopted is unclear. One further point, the overseas student was especially self-critical at the evaluation phase, raising the possibility 
that cultural norms might also influence the outcome of the scoring method. In this case, the tutors raised the marks of the overseas student having observed the effort and contribution made and realising that their own harsh self-assessment was invalid due to low self-esteem resulting from poor language skills.

\section{DISCUSSION QUESTIONS}

The following are the author's responses to a series of questions that have been raised throughout our experiences implementing above process:

Q1 Is it possible to keep the advantages of group projects without becoming entangled in resolving team disputes during the project or dealing with recriminations afterwards?

This paper's authors believe that the advantages outweigh the disadvantages, but that several safeguards must be put in place first to minimise disputes and the time spent resolving them:

- Students should be included in the set-up process and their approval for the system is required. There is inherent value in involving the students in marking schemes right from the outset. The students understand that their evaluations inform the academic team (not prescribe the outcome).

- Teams must be monitored by staff throughout and records of activity, contribution and effectiveness logged.

- Confidential evaluations must be understood to be so and treated as such; otherwise social pressures often distort honest evaluation.

- Including formal delivery on methods of team management or group dynamics such as parallel thinking, decision making or resolving conflicts.

Q2 Is it possible to accurately assign individual marks when only a team project is assessed?

This paper argues that it is but acknowledges that the method described here relies significantly on students' judgements about themselves and each other. In most cases, they show themselves to be fair, reasonable and fully aware of the role they have in affecting a grade that, in some cases, might contribute towards a degree. Although they only evaluate contribution and effort, not academic quality, there is a legitimate discussion to be had about the extent to which this is appropriate. There are also those few cases, where students show themselves not to be fair or reasonable, but to be overly harsh or lenient. The authors consider that students inform the final decision, but the tutor needs to take full, professional responsibility for grades, whilst the students themselves must understand that if the process is abused, they forfeit their chance to influence the grading, having demonstrated a lack of professional maturity or integrity. In the small number of disputed grades, there is a good enough body of evidence (record of attendance, logs of online activity and observations) to guide staff's judgment when arbitrating final marks - ultimately the calculated weighting factor is only advisory and the final decision on its value must be judged by the academic. It is accepted that some tutor time will be spent dealing with anomalies due to collusion or team breakdown, but that significantly more time is saved than lost dealing with such anomalies.

Q3 What are the shortcomings of the current method and how might it be improved?

Further improvement can be made by better preparing students. This may involve formal delivery on methods of team management or group dynamics such as parallel thinking, decision making or resolving conflicts. Students should also be made aware of the significance of the evaluation process by introducing some weighting examples showing the effect of different individual values on the same group mark. The importance of a student's ability to work in a group would suggest that this process should be done regularly throughout their education. The use of periodic anonymous peer-reviews throughout a group project would also allow students to practice the skill regularly as well facilitating the raising and resolving of conflict within the project rather than having to be moderated by assessors after the project's completion. Furthermore, there may be some mileage in identifying distinct roles within the group, possibly aligned with individual areas of perceived expertise or perhaps more importantly, weakness: the manager, the creative, the technician, the communicator etc. In other words, set up a group structure, maybe even a hierarchy, which better reflects the world at large and can be used to best support the professional development of students. In assessing this, the group activity should be complemented by an individual reflective document (e.g. statement of relevance) that shows personal learning reflection (and critical argument). 


\section{CONCLUSIONS}

The value of group projects has been touched on above and discussed more fully elsewhere, but in brief, this paper endorses the view that the positive outcomes include stronger, more independent learning better suited to the professional world whilst using the scarce resource of staff effort more efficiently. In education the trade-off between the accuracy and validity of assessment is a complex one, but we feel the benefits of group work outweigh the complications of implementing it. Students practice evaluation of themselves and their peers and how to deal with this. The weighting method outlined here aims to expose students to the challenges and advantages of group working whilst retaining the beneficial incentive of individual reward. During the project it acts as an incentive to individual team members to contribute. After the project it efficiently calibrates individual contributions, leaving over $90 \%$ of students content that their grade reflects their performance. However, there must be a clear, traceable set of evidence in place to help resolve issues amongst the minority of students that are not satisfied at first.

\section{REFERENCES}

[1] O’Neill, Assessment: Assessing Group Work, UCD teaching and learning resources, 2013. Available: https://www.ucd.ie/t4cms/UCDTLE0065.pdf [accessed on 20/2/2017].

[2] Engineering Council, Institutions licensed to accredit academic programmes, Available: https://www.engc.org.uk/about-us/our-partners/professional-engineering-institutions/ [accessed on $20 / 2 / 2017]$.

[3] Biggs, J., Tang, C. “Teaching for Quality Learning at University”, McGraw-Hill Education (UK), 2011.

[4] Eberly Centre, How can I assess group work? Carnegie Mellon University, 2015. Available: https://www.cmu.edu/teaching/designteach/design/instructionalstrategies/groupprojects/assess.ht $\mathrm{ml}$ [accessed on 20/2/2017].

[5] Freeman, M. "Peer Assessment by Groups of Group Work". Assessment \& Evaluation in Higher Education. 2011, 20(3), p289-300.

[6] Boud, D., Falchikov, N., "Student Self-Assessment in Higher Education: A Meta-Analysis". Review of Educational Research, 1989, 59(4), p395-430.

[7] Hughes, I. E. and Large, B. J. "Staff and Peer-Group Assessment of Oral Communication Skills". Studies in Higher Education, 1993, 18(3), p379- 385.

[8] Ward, M., Gruppen, L. and Regehr, G. "Measuring Self-assessment: Current State of the Art”. Advances in Health Sciences Education. 2002, 7, p63-80.

[9] Brown, R., "Autorating: Getting individual marks from team marks and enhancing teamwork". Frontiers in Education Conference Proceedings. Pittsburgh, IEEE/ASEE, 1995, p3c2.15-3c2.18.

[10] Kaufman, D., Felder, R., Fuller, H., "Accounting for individual effort in cooperative learning teams". Journal of Engineering Education, 2000, 89(2), p133-140.

[11] Oakley, B., Felder, R., Brent, R., Elhajj, I. "Turning Student Groups into Effective Teams, Journal of Student-Centred Learning”, 2004, 2(1), p9-34.

[12] Mannix, E., Griffith, T. and Neale, M.A., "The Phenomenology of Conflict in Distributed Work Teams.” Distributed Work. Distributed Work. 2002. p213-233.

[13] Centre for teaching excellence, Methods for assessing group work, University of Waterloo. Available: https://uwaterloo.ca/centre-for-teaching-excellence/teaching-resources/teachingtips/developing-assignments/group-work/methods-assessing-group-work [accessed on 20/2/2017].

[14] Hey, J., Van Pelt, A. and Agogino, A., "An analysis of student reflections from a multidisciplinary new product development class.", Proceedings of IDETC/CIE 2006 ASME 2006 International Design Engineering Technical Conferences \& Computers and Information in Engineering Conference, Philadelphia, Pennsylvania, USA, September 10-13, 2006. 